\title{
DESIGN OF THE SHAPE OF THE EXPERIMENTAL CHAM- BER FOR THE ANALYSIS OF THE PRESSURE LAYOUT IN THE DIFFERENTIAL PUMPED CHAMBER
}

\author{
Věra Hájková \\ The St. Cyril and Methodius Comprehensive School and Pedagogical High School Brno (3) \\ E-mail: xbayer02@stud.feec.vutbr.cz
}

Supervised by: Jiri Maxa

E-mail: maxa@feec.vutbr.cz

\begin{abstract}
This article is based on a study of Dr. Danilatos, where pumping of the differential pumped chamber is solved using the Monte Carlo statistical method. Similar results were obtained using the Ansys Fluent system. Theoretical computations as Dr. Danilatos and comparative studies are performed on theoretical shape. Simulations were made to obtain the shape of an experimental chamber with complete pumping shapes so that its shaping and pumping would ensure such a flow of gas to ensure the same distribution of pressure in the experimental chamber in the area under investigation as in the theoretical shape.
\end{abstract}

Keywords: Shockwave, ANSYS Fluent, ANSYS Mechanics, Optical methods, Pitot tube, Pressure measurement, Solidworks, Thermography,

\section{INTRODUCTION}

This article is based on a study of Dr. Danilatos [1], which deals with the pumping of the differential pumped chamber in the environmental scanning electron microscope using the Monte Carlo statistical method [2]. Based on these articles, a comparative study [3] was produced, where comparable results were obtained by Continuous Mechanics using the Ansys Fluent system using the finite volume method $[4,5,6]$.

Currently, work is being done to experimentally measure the distribution of pressures and velocities in the area under investigation.

Theoretical computations as Dr. Danilatos and comparative studies are performed on theoretical shape (Fig. 1), which is a very truncated shape, where the boundary conditions are located immediately on the interface of the differentially pumped chamber (Fig. 1), on the contrary, it is necessary to create an experimental chamber with complete pumping shapes so that its shaping and pumping ensures such gas flow, to ensure the same distribution of pressure in the experimental chamber as in the theoretical shape.

\section{RESULTS AND DISCUSSIONS}

After the analysis, the shape of the experimental chamber was projected on figure 2. The profile of the results obtained by the analysis in this experimental shape is shown in the cut-out (Figure 2). It could be seen that the distribution of pressures is practically the same as the theoretical shape.

Comparative analysis were carried out in two key areas. The first is the distribution of pressures on the conical surface, from which the pressure values will be traced in practice and the second is in the axis of the primary electron beam. On (Fig. 3) Is a comparison of pressures on the sloping surface and on (Fig. 4) course velocity in the primary beam axis. 

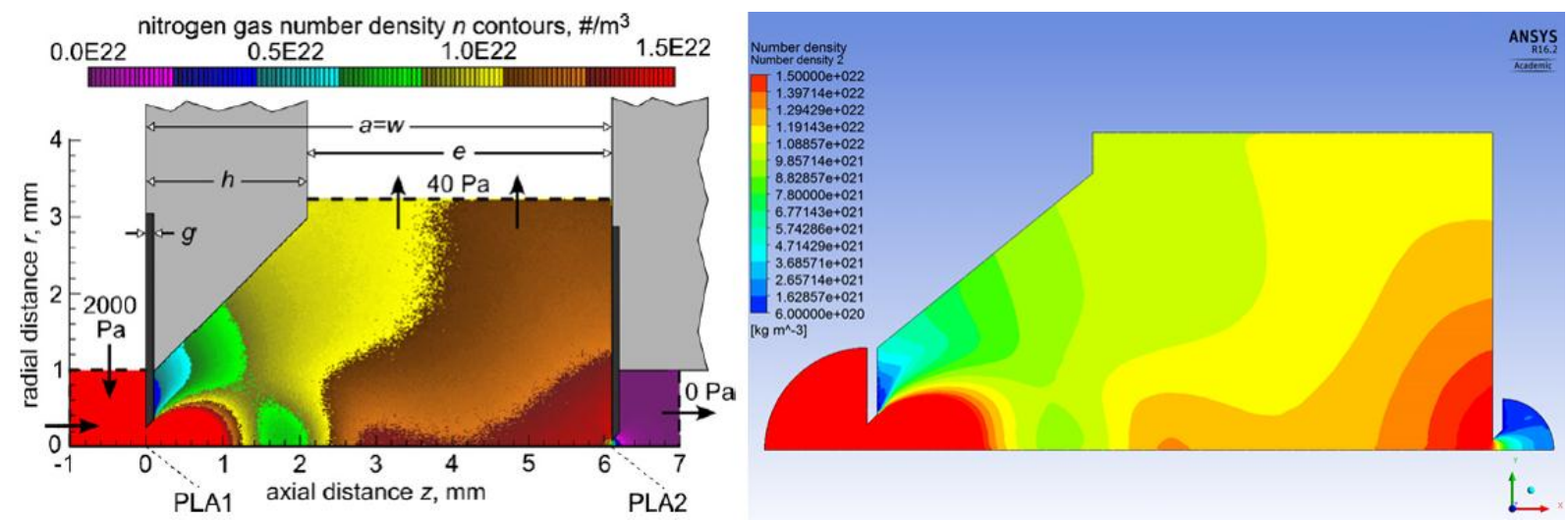

Figure 1: $\quad$ Comparison of simulation results: A - Monte Carlo, B - Mechanics Comtinuum

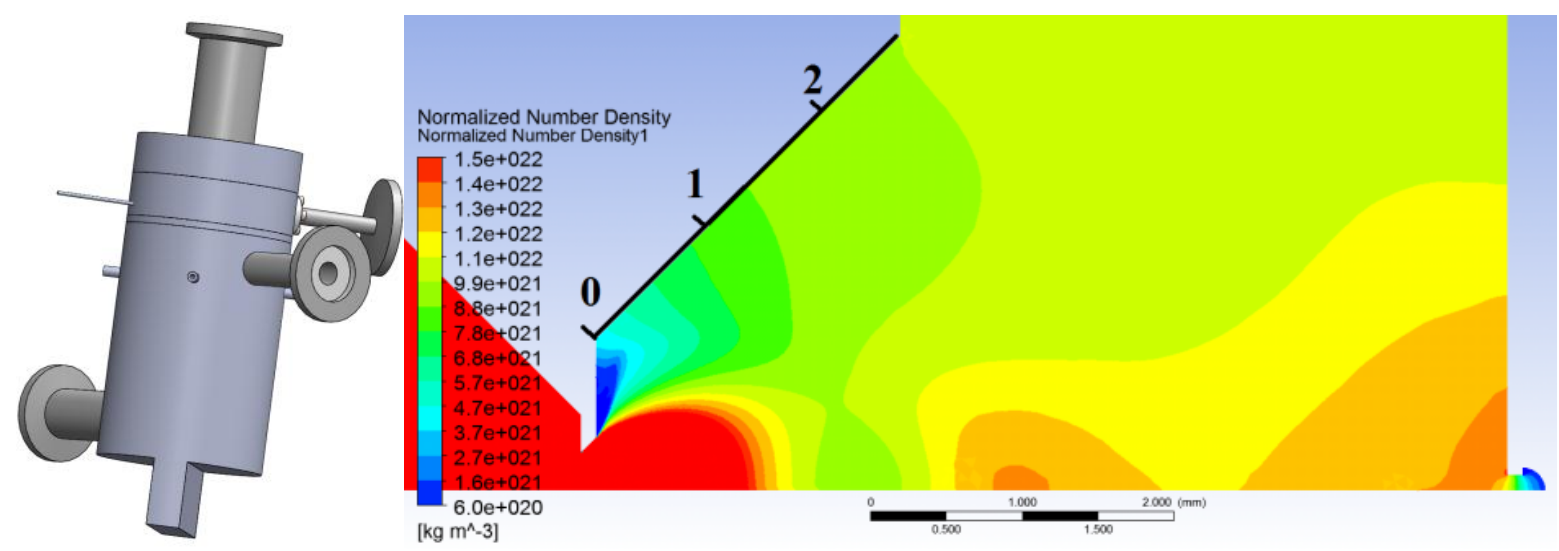

Figure 2: $\quad$ A - Experimental chamber, B - Results for the shape of the experimental chamber

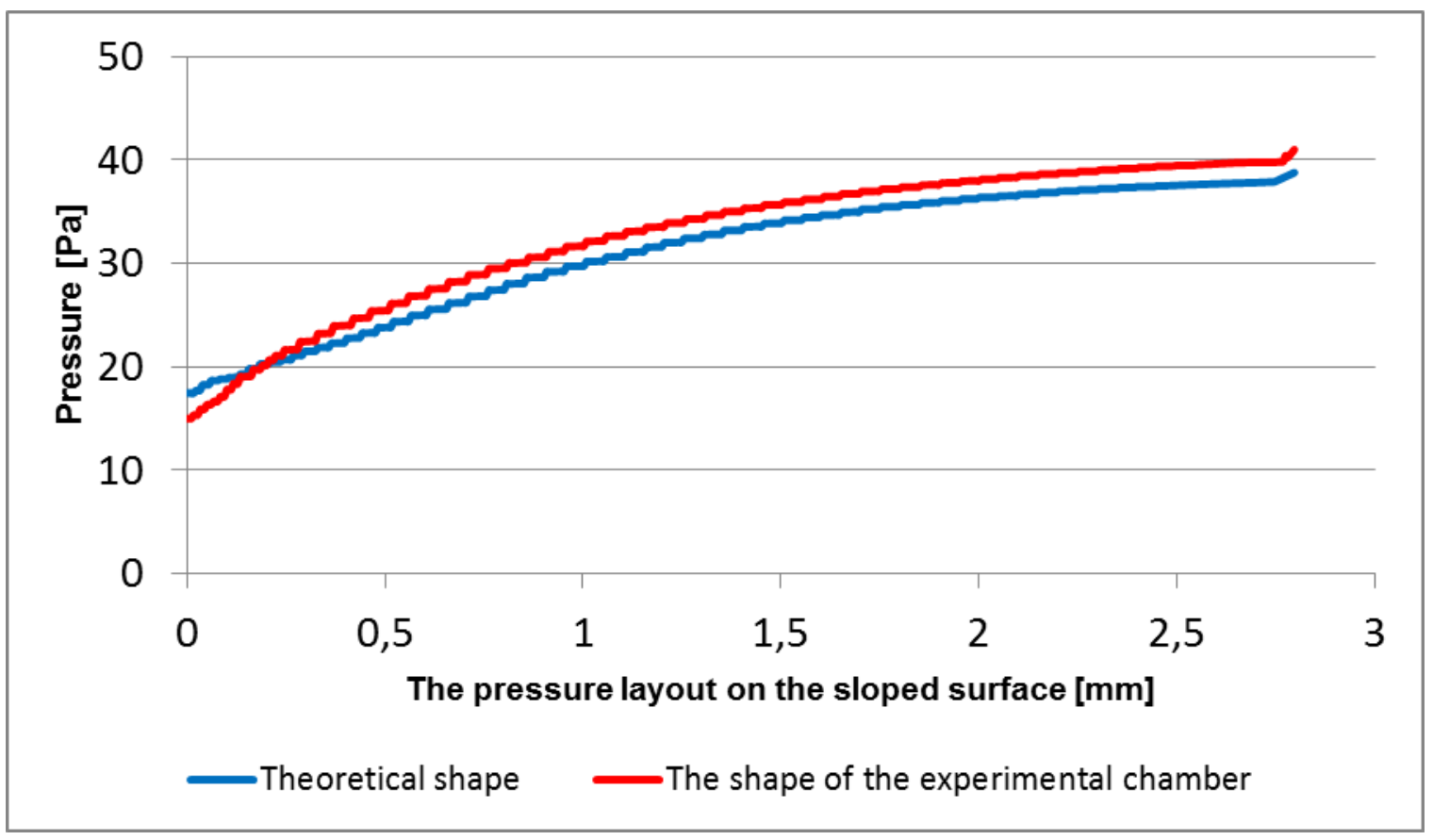

Figure 3: $\quad$ The pressure layout on the sloped surface. 


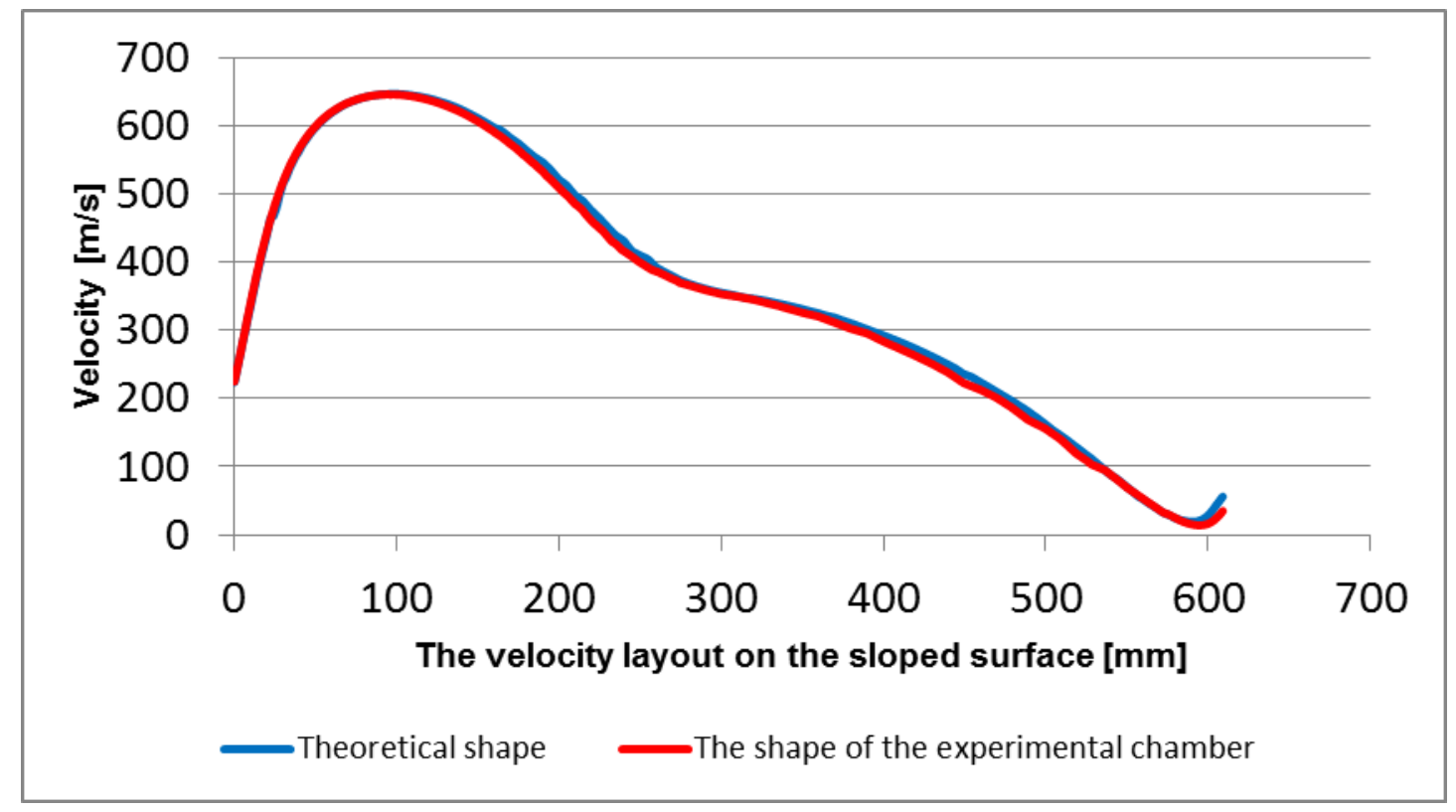

Figure 4: $\quad$ The velocity layout on the sloped surface

\section{CONCLUSION}

The results shows that final design of our shape of experimental chamber results into identical flowing character as theoretical shape and it is suitable for achieving experimental data for tuning system for differential reaching analysis in supersonic regime in low density pressure area.

\section{ACKNOWLEDGMENTS}

This research has been carried out in the Centre for Research and Utilization of Renewable Energy (CVVOZE). Authors gratefully acknowledge the financial support from the Ministry of Education, Youth and Sports of the Czech Republic under NPU I programme (project No. LO1210) and BUT specific research programme (project No. FEKT-S-17-4595).

\section{REFERENCES}

[1] Danilatos, GD.: Velocity and ejector-jet assisted differential pumping: Novel design stages for environmental SEM. Micron, 2012, vol. 43, no. 5, p. 600-611.

[2] Neděla, V.: Controlled dehydration of a biological sample using an alternative form of environmental SEM. Journal of Microscopy. 2010, 237 (1), p. 7-11. ISSN 0022-2720.

[3] Maxa, J., Bílek, M., Hlavatá, P., Vyroubal, P., Lepltová, K.: Comparisons Using Methods of Continuum Mechanics and Monte Carlo at Differentially Pumped Chamber. Advances in Military Technology, 2016, vol. 11, no. 2, p. 143-150. ISSN: 1802-2308.

[4] Vyroubal, P., Maxa, J., Neděla, V., Jirák, J., Hladká, K.: Apertures with Laval Nozzle and Circular Orifice in Secondary Electron Detector for Environmental Scanning Electron Microscope, Advances in Military Technology, 2013, vol. 8, no. 1, p. 59-69.

[5] Maxa, J., Neděla, V.: The Impact of Critical Flow on the Primary Electron Beam Passage through Differentially Pumped Chamber. Advances in Military Technology, 2011, vol. 6, no. 1, p. 39-46. ISSN 1802-2308.

[6] Maxa, J., Neděla, V., Jirák, J., Vyroubal, P., Hladká, K.: Analysis of gas flow in a secondary electron scintillation detector for ESEM with a new system of pressure limiting apertures. Advances in Military Technology, 2012, vol. 7, no. 2, p. 39-44. 